\title{
Da História da Filosofia ao Filosofar: alguns desafios no diálogo com o não filosófico
}

From the history of philosophy to the philosophize: some challenges in the speech with the no philosophical

Elisete Medianeira Tomazetti*

Universidade Federal de Santa Maria

Cláudia Cisiane Benetti**

Universidade Federal de Santa Maria

Resumo Este texto propõe uma reflexão sobre um modo de ensinar e aprender filosofia que se consolidou nos cursos superiores de filosofia e produziu efeitos diferenciados em ensino na escola básica. Destaca os discursos produzidos, nas últimas décadas, no tensionamento entre ensinar filosofia e ensinar a filosofar perpassados pela relação com a História da Filosofia e, tendo como referência as Diretrizes Curriculares Nacionais do Ensino Médio (2012), apresenta um novo cenário escolar em construção. Em tal cenário, está indicado um novo desenho curricular, estruturado por área de conhecimentos, que passa a solicitar dos professores o enfrentamento da questão da interdisciplinaridade e da contextualização dos saberes escolares. Nessas condições, procuramos pensar, de forma inicial, sobre o ensino de filosofia, no contexto da área das Ciências Humanas, com vistas a experiências interdisciplinares.

PalaVRas-Chave: Ensino de Filosofia, História da Filosofia, Ensino Médio, Currículo.

Abstract This text proposes a reflection about a teaching and learning philosophy method that has been consolidated in the philosophy graduation courses and has produced different effects at education in basic school. Highlighting the produced speeches in the last decades, in the tension between teaching philosophy and teaching to philosophize intertwined by Philosophy History and having as reference the High School National Curricular Curriculum Guideline (2012), presents new educational scenery in building. In such scenery its indicated a new curriculum drawing, structured by knowledge fields, that request from the teachers a confrontation of the interdisciplinary question and the school knowledge contextualization. In these conditions, we intend to think, on the beginning, about philosophy education, in the Human Science Field context, with a view to interdisciplinary experiences.

KEYwORDS: Philosophy Education, Philosophy History, High School, Curriculum. 


\section{Introdução}

Talvez se possa afirmar que a história da filosofia seja um dos temas mais mencionados nos estudos e produções bibliográficas quando se trata de pensar e escrever sobre o ensino de filosofia no Brasil, desde o final dos anos 80. O professor Franklin Leopoldo e Silva, em 1986, publicou o texto História da Filosofia: centro ou referencial?, que se tornou uma leitura obrigatória na área. A primeira tese apresentada pelo professor enfatiza que a filosofia não se separa de sua história, ou seja,

A filosofia como saber é tão imanente à sua própria história que não podemos sequer chegar a determinar, com alguma esperança de rigor, uma direção formadora de um corpo teórico, que representasse a filosofia num determinado momento de seu desenvolvimento. Isto significa que o ensino de filosofia recorre à história da filosofia de maneira bem diferente do que se faz no ensino de ciências. (LEOPOLDO E SILVA, 1986, p. 153)

O ensino de filosofia não se faz sem a história da filosofia; no entanto, pode-se tomá-la como o centro do programa de ensino ou como o seu referencial. No primeiro caso, o professor deve "focalizar os sistemas e autores na ordem histórica do seu desenvolvimento, visando familiarizar os alunos com os problemas e as formas de encaminhamento das soluções" (LEOPOLDO E SILVA, 1986, p. 154). A tomada da história da filosofia como referencial, como segunda possibilidade, implicaria a sua entrada em cena na aula, na medida em que os temas tratados lhe requisitem, tendo ela apenas um caráter ilustrativo. "Os temas são tratados independentemente dos sistemas ou autores, levados em conta apenas na medida em que propiciam os indispensáveis referenciais para a discussão" (1986, p. 154).

A escolha de uma ou outra perspectiva implica, segundo o autor, vantagens e desvantagens, as quais não serão abordadas aqui. Interessa-nos pensar, a partir dessa problemática, as condições que a fizeram emergir. Por que o tema da história da filosofia, no âmbito do ensino de filosofia, assumiu essa importância? Não poderíamos vislumbrar, nesse cenário, certo receio de que a história da filosofia estivesse correndo o risco de ser esquecida, por não mais ser ensinada na escola?

O que nos parece razoável pensar é que a entrada do enunciado "importância da história da filosofia no seu ensino", na ordem do discurso do ensino de filosofia, afirmava a necessidade de sua permanência e o reconhecimento de sua importância. No entanto, era preciso deixar explícito que não se tratava de mera repetição e informação histórica. Era preciso, então, um trabalho de apresentação de argumentos que indicassem como continuar ensinando história da filosofia de forma a não tornar a disciplina estéril e sem sentido para os estudantes.

Em outro texto, escrito em 1993, novamente o professor Franklin retoma essa questão, avançando na explicitação de sua perspectiva sobre o ensino de filosofia. Ele afirma que a história da filosofia havia se transformado no "caráter inibidor" da filosofia. 
Como considerar, do ponto de vista da formação, o fato de que, contemporaneamente, o caráter alimentador da história da filosofia se tenha quase que totalmente transformado no seu caráter inibidor? [...] É preciso enfrentar este caráter inibidor da história. [...] Se não se pode deixar de assumir o lugar de onde se pensa e de onde se fala, é preciso também mostrar a inscrição deste lugar na pluralidade histórica, que afinal, é o que lhe confere sentido. A dificuldade aumenta quando consideramos que, a inserção não é apenas na história da filosofia, mas na experiência individual, social e histórica do professor e dos alunos. Se, por um lado, não se pode prescindir desta experiência (ela está presente, quer queiramos ou não), por outro, é assustadoramente difícil estabelecer conexões, de forma a que desta experiência se possam extrair (ou com elas se possam compatibilizar) as questões filosóficas na especificidade mínima que devem aparecer, para evitar o risco da descaracterização. $\mathrm{O}$ acesso à especificidade se dá através da linguagem e do repertório. (LEOPOLDO E SILVA, 1993, p. 801-802)

No centro da problemática, está a história da filosofia. O seu reconhecido caráter alimentador do ensino aparece, nesse texto, como "inibidor". Em que sentido manifesta-se tal caráter? Ora, é inibidor quando se desconsidera a pluralidade de perspectivas filosóficas, filosofias nas quais o professor se situa e deve procurar situar seus estudantes; quando, na aula de filosofia, se desconsidera a experiência individual dos envolvidos e aquilo que ela suscita no desdobramento da aula. Ao mesmo tempo, Franklin Leopoldo e Silva destaca que é "assustadoramente difícil fazer conexões" entre a história da filosofia e as experiências singulares dos sujeitos envolvidos na aula. Parece-nos que essa afirmação, datada no ano de 1993, inaugura outro movimento de pensamento sobre o ensino de filosofia, com o qual estamos, ainda hoje, muito envolvidos, buscando pensar e produzir algumas possibilidades.

No entanto, antes de avançarmos, consideramos necessário compreendermos a matriz que marca a nossa tradição de ensino de filosofia no século XX, a partir da criação do Departamento de Filosofia da Universidade de São Paulo, nos anos de 1940.

\section{Modo de leitura estrutural do texto filosófico como história da filosofia}

A expressão história da fllosofia perpassa a constituição da própria filosofia, seja como problema teórico, seja como questão pedagógica, e, apesar dessa recorrência, o que há são controvérsias sobre aspectos metodológicos, tanto em um caso como em outro. Percebe-se sua centralidade, no processo de institucionalização da filosofia, como conteúdo acadêmico, que se tornou conhecido como o "modelo uspiano".

O professor Jean Maugüé, que foi responsável pelos cursos de Filosofia da USP entre os anos de 1935 e 1944, afirma que "a base do ensino da filosofia no Brasil é a história da filosofia" (MAUGÜÉ, 1955, p. 646). Apesar da importância dada ao caráter subjetivo do filosofar, tais condições propõem a centralidade do texto clássico como garantia da especificidade da filosofia. Além disso, estabelece uma concepção pedagógica muito clara ao especificar que há uma ordenação na aprendizagem filosófica: em primeiro lugar, os estudantes devem ter um nível cultural mínimo; depois, 
devem ler os clássicos para aprender como se faz filosofia; e então, se atingidas tais exigências de conhecimentos, eles poderão pensar em proposições externas ao texto e à tradição, efetivando uma filosofia mais autoral.

As normas moldadas por Maugüé demarcam a importância de reportar os estudos filosóficos aos clássicos, com o fim de estabelecer uma base de conhecimentos densa e evitar o deslize para o pensamento sem referências na tradição, uma vez que a produção filosófica brasileira, até então, assumia um caráter literário e retórico, situada como "uma espécie de ramo especulativo do bacharelismo" (ARANTES, 1994, p. 174). No entanto, é necessário, desde já, esclarecer o que se deve entender, segundo Maugüé, pela dimensão histórica da filosofia: "Naturalmente, a história não é erudição. O professor deverá constantemente traduzir o sentido da obra que estudar em termos atuais" (MAUGÜÉ, 1955, p. 647). E o professor finaliza, de maneira enfática, afirmando: "A História da Filosofia deve ter, no Brasil, um lugar primordial. Ela pode ser ensinada, seguindo métodos rigorosos e perfeitamente modernos. Não há vida presente sem o conhecimento da vida passada" (p. 649).

Em seu livro Um departamento francês de ultramar (1994), Paulo Arantes descreve o período em que fora estudante de Filosofia, na Rua Maria Antônia (endereço do Departamento de Filosofia da USP), na década de 1960. Ele destaca a importância da presença das ideias de Victor Goldschmidt e de Martial Gueroult, trazidas pelo professor Oswaldo Porchat Pereira. Assim, juntamente ao programa de Jean Maugüé, as concepções daqueles dois autores definiram um modo peculiar de se estudar filosofia. Os textos Tempo histórico e tempo lógico na interpretação dos sistemas filosóficos (1963), de Goldschmidt, e Le problème de l'histoire de la philosophie (s/d), de Gueroult, podem ser considerados marcos do que Arantes denominou "o momento mais alto da metodologia científica em história da filosofia, uma jovem disciplina que o método dito 'estrutural' afinal elevara à real objetividade das ciências rigorosas e em torno da qual gravitaria o ensino da filosofia entre nós” (1994, p. 17). Constituía-se, naquele momento, um método para estudar e aprender filosofia nos trópicos. Esse método exigia a leitura dos clássicos, que deveria ser "comandada pelos olhos do espírito, esforço de compreensão interna, como se dizia então (até Merleau Ponty), de costas para a matéria bruta da experiência social" (ARANTES, 1994, p. 17). A contribuição de Goldschmidt (1963) refere-se à leitura do texto em seu movimento interno, sua estrutura e sua lógica. Assim se explica sua proposta metodológica:

A filosofia é explicitação e discurso. Ela se explicita em movimentos sucessivos, no curso dos quais produz, abandona e ultrapassa teses ligadas umas às outras numa ordem por razões. A progressão (método) desses movimentos dá à obra escrita sua estrutura e efetua-se num tempo lógico. A interpretação consistirá em reapreender, conforme a intenção do autor, essa ordem por razões, e em jamais separar as teses dos movimentos que as produziram. (GOLDSCHMIDT, 1963, s/p)

Destaca-se a centralidade do texto e da escrita, mas também o papel do historiador da filosofia, o qual consiste na interpretação e na apreensão do método, sendo este o objeto da análise. Nesse sentido, a verdade do texto constitui-se em sua lógica 
interna, antes mesmo de qualquer correspondência material. $O$ método é, em si, verdadeiro e, por conseguinte, não cabe ao intérprete-historiador-filósofo ${ }^{1}$ questionar sobre a correspondência com o mundo externo. Desse modo, Goldschmidt complementa:

Assim, para compreender uma doutrina, não é suficiente não separar a léxis da crença, a regra, de sua prática; é preciso, após o autor, refazer os movimentos concretos, aplicando as regras e chegando a resultados que, não por causa de seu conteúdo material, mas em razão desses movimentos, se pretendem verdadeiros. (GOLDSCHMIDT, 1963, s/p).

A aprendizagem, então, consiste em refazer esse caminho racional estabelecido pelo filósofo, apreendendo cada passo do método filosófico. O método se materializa no texto que, por sua vez, constitui a tradição. Dessa forma, conforme palavras do próprio Goldschmidt, faz-se uma "exegese dos métodos".

Tendo como referência os princípios que nortearam a produção filosófica dentro da universidade brasileira, a partir do Departamento de Filosofia da USP, a questão que nos ocorre diz respeito aos efeitos produzidos por essa forma de ensinar e de aprender. Certamente, não podemos deixar de compreender a importância da mudança operada com esse método naquele período, pois, como descreve Gilda de Mello e Souza (ARANTES, 1994, p. 67), o ensino da filosofia não se dava mais pela "repetição mecânica de um texto, vazio e inatual, cujas fontes eram cuidadosamente escamoteadas da classe, mas a exposição de um assunto preciso, apoiado numa bibliografia moderna, fornecida com lealdade ao aluno [...]. [...] o professor consultava disciplinadamente as suas anotações, aumentando com isso a confiança dos alunos na seriedade do ensino". Contudo, é necessário ressaltar, como o faz Arantes (1994, p. 67): "história quer dizer aqui simplesmente retorno aos textos eles mesmos".

Retomando as concepções canônicas sobre o ensino de filosofia, elaboradas no âmbito universitário, é possível situar a história da filosofia como marco referencial de exemplos do fazer filosófico. Conforme a vontade dos precursores franceses, o objeto a ser apreendido seria o método filosófico. A possibilidade de repeti-lo e de atualizá-lo consistiria no fazer filosófico legítimo.

Consideramos importante, então, visualizar, pela estrutura curricular dos cursos de Filosofia, o tipo de herança que tal concepção deixou. Cientes da importância da leitura estrutural do texto filosófico, que o vinculava à tradição, ao seu tempo histórico, destacamos, entretanto, que, na universidade, a compreensão do estudo da filosofia pela sua história foi tomada, também, como uma indicação cronológica e evolutiva, modificando a concepção inicial ou a ela somando-se.

Por sua vez, a atenção à estrutura do texto deixou em suspenso a preocupação com o nível seguinte da tarefa filosófica, qual seja, o da relação autoral com problemas filosóficos que não os explicitados no texto mesmo, com o que fica externo ao texto, mas é do tempo presente. Por isso, esse modo de fazer filosofia não ficou imune a críticas. Haveria efeitos nefastos produzidos pela sobrevalorização que o texto tomou nos estudos universitários de filosofia no Brasil. Alguns desses efeitos são destacados por Pimenta: 
As consequências pedagógicas são facilmente identificadas: uma filosofia estéril, um "pensamento tímido". A expressão pensamento tímido designa uma atitude de demasiada reserva ou medo de ousar. $\mathrm{E}$ isto de duas maneiras. Primeiro, ousar na hermenêutica e, segundo, ousar no diálogo intenso com o texto. (PIMENTA, 2010, p. 3).

Considerando essa tradição de estudo da filosofia no Brasil, que atravessou o século XX e ainda se faz presente, podemos perceber que, em anos mais recentes, embalados pelo retorno obrigatório da disciplina à escola, os estudiosos passaram a manifestar suas críticas a esse modelo e indicar que tal não poderia ali ser repetido. Por isso, a ênfase constante nos textos, debates e seminários sobre o "não ensino da história da filosofia" na escola, história esta entendida como "leitura estrutural do texto filosófico", mas, também, como "evolução cronológica de todas as filosofias produzidas ao longo da tradição".

\section{Crítica ao ensino da História da Filosofia: o que colocamos em seu lugar?}

É necessário destacar que o entendimento da expressão "história da filosofia", ao longo dos anos, não se manteve fiel à tradição uspiana, mas foi se modificando e assumindo um significado cronológico e evolutivo, expressos nos excertos abaixo:

Um dos aspectos mais polêmicos em relação aos conteúdos programáticos da filosofia no ensino médio refere-se à sua relação com a história da filosofia. [...] O modelo mais tradicional de programa centrado na história da filosofia consiste em apresentar uma sequência cronológica dos pensadores, desde Tales de Mileto até hoje, numa abordagem que prescinde do contato direto com o pensamento dos filósofos, restringindo-se basicamente a uma narração e síntese da vida, obra e principais ideias dos filósofos, organizados de modo classificatório, segundo sistemas de pensamento a que estão vinculados. (RODRIGO, 2009, p. 44-45).

[...] ensinar filosofia significa ensinar o que a história da filosofia produziu até hoje - mesmo que dificilmente se chegue até os filósofos do presente. Geralmente essa história é compreendida como os mais de 25 séculos de existência da filosofia ocidental e seus desdobramentos. (GALLO; KOHAN, 2000, p. 177).

Como podemos perceber, o ensino da filosofia, naquelas escolas em que continuou sendo oferecido, acabou se constituindo pela transmissão de informações, ideias e conceitos de filósofos, apresentados segundo uma direção cronológica e evolutiva.

A crítica a esse modo de ensinar e aprender filosofia não tardou a ocorrer. Considerando algumas produções sobre o tema, a partir dos anos 90, percebem-se tentativas de problematizar esse discurso, procurando destacar a dimensão da atividade filosófica, do professor e do aluno, no espaço da sala de aula. O texto "Notas sobre ensino de filosofia", do professor Celso Favaretto, publicado no livro Filosofia e seu Ensino (1996), pode ser considerado uma referência e um deflagrador de outra 
perspectiva para o ensino de filosofia na escola. As teses desse texto foram retomadas, mais tarde, por ocasião da produção dos Parâmetros Curriculares Nacionais do Ensino Médio (PCNEM, 2000). No referido texto, o autor destaca a não univocidade de uma concepção de filosofia como matriz para o ensino, mas a existência de "filosofias", "pois, face à sua dispersão, a Filosofia não mais se apresenta como um corpo de saber e, assim, não se propaga da mesma forma como um saber que se transmite (...)" (FAVARETTO, 1996, p. 77). O ensino da filosofia, na escola, não poderia ser pensado, então, como a transmissão de um corpo de conteúdos, "mas daquilo que possa garantir a entrada nos procedimentos filosóficos” (1996, p. 77).

Novos enunciados passam a compor o discurso do ensino de filosofia na escola, e a palavra "procedimentos" vai, aos poucos, sendo agregada a outras: atividade filosófica", "exercício filosófico", "filosofar". Considerando a importância de o professor de filosofia ter claro para si mesmo a sua concepção de filosofia e qual a "imagem de Filosofia que ele visa efetivar com seus alunos" (FAVARETTO, 1996, p. 78), é preciso, então, definir e escolher uma maneira de garantir a sua entrada nos "procedimentos filosóficos”. Que são tais procedimentos? E o professor Favaretto responde: é a "produção da familiaridade com um modo de linguagem que articula fabricação de conceitos, argumentação, sistematicidade e significação" (1996, p. 78). De forma bem clara, é afirmado que cabe ao professor estabelecer conexões com o "vivido", com o tempo presente de seus alunos adolescentes. "(...) os 'eu acho que', liberados em conversas, discussões, redações, podem sempre permitir o acesso a problemas filosóficos, sem imprimir a inabilidade teórica ou a manifestação emocional dos alunos" (1996, p. 78). O que caberia ao professor seria proporcionar a inteligibilidade de seus alunos acerca de suas opiniões e dos textos filosóficos e não filosóficos, através de "exercícios operatórios", que, em filosofia, diz o professor Favaretto (1996, p. 81), "visam ao desenvolvimento de habilidades em construir e avaliar proposições, em determinar os princípios subjacentes a elas, o que passa pelo sentido das palavras e pela atenção à cadeia sintática, pelo menos".

Entre o enunciado História da Filosofia é fundamental para o ensino da filosofia, e Ensinar a filosofar, proporcionar o desenvolvimento da atividade filosófica, passamos algumas décadas considerando ora sua relação de exclusão, ora sua relação de indissociabilidade. Nesse sentido, os estudos de Kant e de Hegel, no que se refere ao ensino de filosofia, passaram a ser um capítulo essencial em seminários, congressos e produções da área, enfatizando a necessidade ora da História da Filosofia, ora do Ensino do Filosofar, muitas vezes descolados do conjunto de sua filosofia, ou seja, colocando no centro das reflexões a questão da melhor metodologia a ser seguida. Nesse cenário, o professor Gelamo (2009, p. 82) afirma: "vemos as propostas de Kant e Hegel ressoarem nas ideias dos pesquisadores e dos professores, porém de modo a retirar algumas imagens daquilo que esses autores pensaram, para adaptá-las ao contexto contemporâneo". Na sequência, Gelamo declara que, se permanecermos "no mesmo registro criado a partir de uma equívoca apropriação de Kant e Hegel e, de maneira mais geral, do modo como o ensino da Filosofia foi e está sendo tratado, não poderemos pensar outros problemas e mesmo outros modos de se ensinar a Filosofia" (2009, p. 83). 


\section{Algumas ponderações sobre o cenário atual do ensino de filosofia}

Após ter apresentado essa rápida reflexão sobre alguns elementos que compuseram a tradição do ensino de filosofia no Brasil, com seus efeitos na escola básica, consideramos necessária uma problematização acerca da situação e dos desafios que estão postos para a filosofia na escola pública brasileira hoje. Desde a inclusão obrigatória da filosofia no currículo do ensino médio, em 2008, a temática tratada na primeira parte desse texto tem arrefecido, o que nos leva a pensar que a superamos e passamos a outras, talvez mais urgentes. Podemos dizer que superamos o velho dualismo: ou se ensina filosofia ou se ensina a filosofar, ou seja, reconhecemos o "caráter alimentador" da história da filosofia para o ensino de filosofia, mas ainda carecemos de um pensar mais efetivo sobre como realizar conexões entre a filosofia e a vida, entre a história da filosofia e as singularidades de alunos e professor na aula, entre a filosofia e as outras disciplinas escolares.

A pesquisa que temos desenvolvido desde $2010^{2}$, cujo objetivo geral é compreender o movimento histórico de criação do Fórum Sul de Coordenadores dos Cursos de Filosofia e do respectivo evento - Simpósio Sul-Brasileiro sobre Ensino da Filosofia - e sua contribuição para o delineamento epistemológico e político da área, apontou para o fato de que os discursos sobre ensino de filosofia permaneceram atrelados à importância do retorno da Filosofia nas escolas, à necessidade de reavaliar os modelos de ensino desenvolvidos e à necessidade de reformulação dos currículos dos cursos de Licenciatura em Filosofia. No entanto, poucos estudos apresentaram reflexões acerca da articulação entre metodologias, didáticas e currículos mais afinados com as demandas educacionais do nosso tempo. Ademais, percebemos que, junto às dificuldades de articulação das produções sobre ensino de filosofia com questões didáticas e metodológicas, está implícito outro problema que os professores de filosofia e pesquisadores enfrentam, qual seja, a da reduzida aproximação da filosofia com o mundo escolar. Por conseguinte, atualmente somos provocados, também, a pensar sobre a filosofia no contexto de outra organização do currículo escolar, definida nas Diretrizes Curriculares Nacionais do Ensino Médio (DCNEM), homologadas em 2012. Esta reformulação propõe um "redesenho curricular", tendo como um dos focos principais a formação integral dos estudantes, a interdisciplinaridade e a organização do currículo por área do conhecimento.

Do ponto de vista das políticas públicas educacionais, do período compreendido entre o ano de homologação da LDB-9394 (1996) e o ano da inclusão da obrigatoriedade da filosofia (e sociologia), em 2008, até esse momento, verificamos um movimento para a "reestruturação" do ensino médio, a partir das DCNEM de 1998 e 2012. Dentre os vários elementos que compõem cada um desses documentos, ressaltamos, aqui, a defesa de um currículo organizado por área de conhecimento. Especialmente as DCNEM de 2012, em seu Capítulo I - Organização Curricular, no primeiro e segundo parágrafo, expressam claramente: 
$\S 1^{\circ} \mathrm{O}$ currículo deve contemplar as quatro áreas do conhecimento, com tratamento metodológico que evidencie a contextualização e a interdisciplinaridade ou outras formas de interação e articulação entre diferentes campos de saberes específicos.

$\S 2^{\circ} \mathrm{A}$ organização por áreas de conhecimento não dilui nem exclui componentes curriculares com especificidades e saberes próprios construídos e sistematizados, mas implica no fortalecimento das relações entre eles e a sua contextualização para apreensão e intervenção na realidade, requerendo planejamento e execução conjugados e cooperativos dos seus professores. (DCNEM, 2012).

A filosofia compõe a área das Ciências Humanas, juntamente com a Sociologia, a História e a Geografia. "O tratamento metodológico", ou seja, o desenvolvimento do currículo, deverá estar sustentado na "contextualização e na interdisciplinaridade", primeiramente no âmbito da área de conhecimento e depois entre as demais áreas, quais sejam: Linguagens, Matemática e Ciências da Natureza.

No que se refere à proposta de reestruturação curricular do ensino médio (DCNEM, 2012), consideramos que há muito que se discutir sobre os princípios epistemológicos da proposta; no entanto, é relevante salientar que há uma abertura que possibilita promover problematizações importantes no campo da formação do professor de filosofia e, consequentemente, em sua atuação na escola.

Podemos afirmar que, no âmbito específico do ensino de filosofia, das práticas realizadas nas aulas, estamos percebendo o avanço nas interações da Filosofia com a área das Linguagens, através de conexões com cinema, música, literatura, para pensar um modo de aproximação de conceitos filosóficos com as culturas juvenis. No entanto, são produções ainda solitárias, que não incluem trocas com as diferentes disciplinas que constituem as Linguagens e que não viabilizam atravessamentos de outras disciplinas, quiçá de outras áreas.

O redesenho curricular proposto para o ensino médio objetiva integrar disciplinas e áreas, instigando o enfrentamento da fragmentação e da especialização, os quais constituíram modos de produzir conhecimento ao longo de séculos. Sabemos que não é um tema novo, mas é um tema que se recoloca em cena conjuntamente com a demanda de outras práticas pedagógicas que potencializem a experiência de diferentes modos de pensar, agir e construir o conhecimento na escola junto aos jovens alunos.

\section{História e tempo presente: desafios e possibilidades para o diálogo entre as disciplinas}

Considerando as demandas por integração, inter-relações e contextualização dos conhecimentos entre as disciplinas da área específica, bem como com outras áreas, conforme o proposto nas DCNEM-2012, buscamos inspiração no projeto filosófico de Foucault para pensarmos os desafios e as potencialidades de estabelecer um diálogo entre as disciplinas que compõem as Ciências Humanas, e destas com as demais áreas. Consideramos que este é um tema complexo que merece maior análise e 
reflexão; no entanto, neste momento, lançamos questões que nos parecem pertinentes para a discussão no campo do ensino de filosofia.

\section{Conforme Fonseca (2011), os escritos de Michel Foucault}

[...] colocam em correlação vários campos de investigação e, mais precisamente, diversas áreas do conhecimento, rompendo muitas vezes os limites precisos entre disciplinas e saberes já estabelecidos. Os temas tratados (o sujeito, o poder, a norma, o discurso, a sexualidade, a ética, etc.), assim como os métodos desenvolvidos para discuti-los (a história arqueológica, a genealogia, o eixo da subjetivação), sugerem uma abordagem que implica realizar continuamente alguns cruzamentos entre esses campos, áreas ou disciplinas. (FONSECA, 2011, p. 131).

Conforme Fonseca (2011), a perspectiva de trabalho filosófico de Foucault “implica realizar continuamente alguns cruzamentos" entre campos, áreas e disciplinas. Tal abordagem está calcada em um projeto filosófico que mantém sempre o "vínculo com questões históricas e político-culturais, o pensamento sobre o presente e a afirmação da necessidade e importância de unir filosofia e atualidade" (CALOMENI, 2011, p. 160).

Pensamos que manter o vínculo com questões históricas, políticas, culturais, situando o pensamento sobre o presente, é um caminho potente para articular relações entre as disciplinas e áreas, construindo projetos em que o trabalho com conceitos seja o motor para deflagrar ações integradas para o desenvolvimento de aprendizagens contextualizadas. Sabemos que o trabalho conceitual é uma característica singular do filósofo; no entanto, pensamos que os conceitos se fazem no cruzamento com diferentes conhecimentos e campos do saber. Daí emergem possibilidades para se pensar em temáticas ou problemáticas do presente, que nos afetam e perpassam a escola cotidianamente. Conforme Feitosa (2004, p. 27), "os conceitos têm história, se encarnam e efetivam nos corpos. Os conceitos não são verdades absolutas e eternas, mas estratégias do pensamento para lidar com problemas e questões".

Entender que conceitos não são verdades absolutas e tomá-los como estratégias para lidar com questões e problemas do presente parece-nos ser uma primeira atitude a ser assumida para, então, buscar enlaces entre as disciplinas da área de ciências humanas e também de outras as áreas. Outra atitude é buscar o entendimento das condições de emergência de um modo de pensar e os efeitos deste nas ações do tempo presente, ações estas que são expressões de conceitos que "têm história, se encarnam e se efetivam nos corpos" (FEITOSA, 2004, p. 27).

Considerando os aspectos acima, lançaremos algumas pistas, que, certamente, merecerão um tratamento mais apurado posteriormente, e que por ora se colocam como potências na composição de estratégias diante dos desafios que nos são postos atualmente.

Pensamos que é relevante construir um espaço de reflexão entre os professores de diferentes disciplinas que compõem as Ciências Humanas e outras áreas, 
buscando selecionar temáticas que emergem como problemas vivenciados pelos jovens e a comunidade escolar. A partir disso, o trabalho coletivo é essencial, para que se promovam encontros entre diferentes conceitos no campo das disciplinas específicas e, junto a isso, procurem-se estratégias para o entrecruzamento entre as leituras possíveis das disciplinas frente à problemática e/ou à temática trabalhada. Ao tomarmos uma problemática que afeta a escola no seu cotidiano e diz do tempo presente, é fundamental a busca pelo entendimento do por que pensamos e agimos no presente de tal modo e não de outro.

A construção de tal entendimento pode se dar pelo entrelaçamento de conceitos filosóficos aos conceitos da geografia, sociologia, história, cruzando a temática e/ou problemática com as leituras específicas de cada disciplina e com as demais áreas. Nesse caminho, o importante é buscar a compreensão das condições de emergência de um modo de pensar e agir e os efeitos no nosso tempo, em nosso modo de agir na comunidade, na escola e na vida. Quando falamos em condições de emergência, estamos propondo a leitura histórica que permite à Filosofia, à História, à Sociologia, à Geografia, às Linguagens, às Ciências Naturais e à Matemática situar os acontecimentos de uma época e os efeitos dos mesmos no tempo presente. Dito de outro modo, a partir da temática escolhida, quais conceitos na Geografia, na História, na Filosofia, na Sociologia e nas Linguagens são propícios para dar conta de entender por que pensamos e agimos de um determinado modo no presente? Quais mudanças e acontecimentos são marcantes nas Ciências Naturais e na Matemática, frente à temática proposta, que se expressam em nossos modos de pensar e agir no mundo na atualidade? E mais, como este modo de pensar se mostra em nossa escola, comunidade e sociedade?

Obviamente que são necessários recortes de conteúdos; no entanto, os conceitos que emergem nas diferentes disciplinas podem ser um elemento de inter-relação para se iniciar um processo de enfrentamento da especialização e da fragmentação que constituiu, e ainda constitui, nosso modo de pensar e ensinar, uma vez que os olhares históricos marcados pela relação com as condições de emergência e efeitos no presente, não ocorrem de forma desvinculada de mudanças e acontecimentos que constituem e refletem modos de vida construídos em determinadas condições sociais, históricas políticas e culturais.

Assim, entendemos que alguns dos desafios que compõem o cenário atual para o ensino de filosofia se afirma em torno da necessidade de construção de metodologias, didáticas e currículos mais afinados com as demandas educacionais do nosso tempo. Tais demandas estão ancoradas na busca de conexões da filosofia como mundo vivido, na contextualização dos saberes filosóficos no espaço escolar e na necessidade de pensar relações interdisciplinares, as quais poderão viabilizar experiências de aprendizagem que conectem o filosófico e o não filosófico.

\section{Referências}

ARANTES, P. E. Um departamento francês de ultramar: estudos sobre a formação da cultura filosófica uspiana. Rio de Janeiro: Paz e Terra, 1994.

BRASIL. Constituição (1988). Constituição da República Federativa do Brasil. Brasília, DF, Senado, 1988. 
BRASIL. Lein.11.684/2008. Disponívelem: <http://www.planalto.gov.br/ccivil_03/_Ato20072010/2008/Lei/L11684.htm\#art1 >. Acesso em: 04 out. 2010.

BRASIL. MEC. Lei n. 9.394, de 20 de dezembro de 1996 - Lei de Diretriz e Bases da Educação Nacional. Disponível em: http:/www.planalto.gov.br/ccivil_03/Leis/L9394.htm. Acesso em: 04 out. 2014.

BRASIL. Ministério da Educação. Conselho Nacional de Educação. Câmara de Educação Básica. Resolução n. 2, de 30 de janeiro 2012. Define Diretrizes Curriculares Nacionais para o Ensino Médio.

BRASIL. Parâmetros Curriculares Nacionais do Ensino Médio. Ciências Humanas e suas Tecnologias. Secretaria de Educação Média e Tecnológica, Brasília, 2000.

CALOMENI, T. C. B. A intempestividade da filosofia: a tarefa filosófica de pensar o presente. In: RESENDE, H. (Org.). Michel Foucault: Transversais entre educação, filosofia e história. Belo Horizonte: Autêntica, 2011, p. 153-170.

FEITOSA, C. Explicando a filosofia com arte. Rio de Janeiro: Ediouro, 2004.

FONSECA, M. A. da. O cruzamento entre a filosofia, a história e a educação na interpretação foucaultiana do diálogo do Alcebíades. In: RESENDE, H. (Org.). Michel Foucault: Transversais entre educação, filosofia e história. Belo Horizonte: Autêntica, 2011, p. 131-142.

GALLO, S.; KOHAN, W. Crítica de alguns lugares comuns ao se pensar a filosofia no ensino médio. In: GALLO, S.; KOHAN, W. (Org.). Filosofia no ensino médio. Petrópolis, RJ: Vozes, 2000.

GELAMO, R. P. O ensino da filosofia no limiar da contemporaneidade: o que faz o filósofo quando seu ofício é ser professor de filosofia. São Paulo: Cultura Acadêmica, 2009.

GOLDSCHMIDT, V. Tempo lógico e tempo histórico na interpretação dos sistemas filosóficos. In: A religião de Platão. Trad. Ieda e Osvaldo Porchat. São Paulo: Difusão Européia do Livro, 1963.

LEOPOLDO E SILVA, F. Currículo e Formação: o ensino da filosofia. Revista Síntese Nova Fase, Belo Horizonte, v. 20, n. 63, 1993.

LEOPOLDO E SILVA, F. História da filosofia: centro ou referencial? In: NETO, H. N.(Org.). O ensino de filosofia no $2^{\circ}$ grau. São Paulo: SOFIA: SEAF, 1986. p. 153-162.

LEOPOLDO E SILVA, F. Notas sobre ensino de filosofia. In: ARANTES, P.; SILVA, F. L.; FAVARETTO, C.; FABRINI, R.; MUCHAIL, S. T. (Org.). A filosofia e seu ensino. Petrópolis: Vozes; São Paulo: EDUC, s/d

MAUGÜÉ, J. O ensino de filosofia: suas diretrizes. Revista Brasileira de Filosofia, v. 5, fasc. 4, n. 20, p. 642-649, 1955.

PIMENTA, A. O ensino de filosofia no Brasil: um estudo introdutório sobre sua história, método e perspectiva. Disponível em: <http://pt.scribd.com/doc/37562775/o-ensino-de-filosofiano-brasil-pimenta>. Acesso em: 16 set. 2012.

RODRIGO, L. M. Filosofia em sala de aula: teoria e prática para o ensino médio. Campinas, SP: Autores Associados, 2009. 
Da História da Filosofia ao Filosofar: alguns desafios no diálogo com o não filosófico

\section{Notas}

${ }^{1}$ Goldschmidt (1963) utiliza, ao longo do texto, os três termos para referir o processo de pesquisa em filosofia.

${ }^{2}$ Texto sobre a referida pesquisa apresentado no VII Colóquio Internacional de Filosofia da Educação, na Universidade Estadual do Rio de Janeiro (UERJ), em 2014.

* Professora Doutora da Universidade Federal de Santa Maria, Santa Maria, Rio Grande do Sul, Brasil.

** Professora Doutora da Universidade Federal de Santa Maria, Santa Maria, Rio Grande do Sul, Brasil.

\section{Correspondência}

Elisete Medianeira Tomazetti - Universidade Federal de Santa Maria, Centro de Educação. Camobi. CEP: 97105900, Santa Maria, Rio Grande do Sul, Brasil.

E-mail: elisetem2@gmail.com - elisetem2@gmail.com

Recebido em 18 de outubro de 2014

Aprovado em 10 de dezembro do 2014 
